\title{
Pengaruh Keselamatan dan Kesehatan Kerja Terhadap Kinerja Karyawan
}

\author{
Ulfa Nurul Nissa $^{1 *}$ dan Sholihati Amalia ${ }^{2}$ \\ ${ }^{1}$ Jurusan Administrasi Niaga, Politeknik Negeri Bandung, Indonesia \\ 2 Jurusan Administrasi Niaga, Politeknik Negeri Bandung, Indonesia
}

\begin{abstract}
:
The purpose of this research is to know the extent of the influence of labor safety and health variables on performance of employees part of the AMT I in PT Pertamina Patra Niaga (Persero) Ujung Berung. For the method used in this research is to use quantitative methods, while for the collection of data is caaried out by means of disseminating a questionnaire to 128 employees part of the AMT I note that median value of median of the descriptive variables - safety and health work is 4,12 while for variable performance of employees is amounted to 4,09. Then from the results of a simple linear regression analysis showed that the work safety and health variables have an influence positively against variable employee performance, can be seen in results from t count i.e of 11,365 and t table of 1,9790. Then the probability values can be found in this study is 0,000 meaning that this regression model can be used to predict the performance.
\end{abstract}

Keywords: safety and health, performance, employees

\begin{abstract}
Abstrak:
Tujuan dari penelitian ini adalah untuk mengetahui sejauh mana pengaruh variabel keselamatan dan kesehatan kerja terhadap kinerja karyawan bagian AMT I di PT Pertamina Patra Niaga (Persero) Ujung Berung. Untuk metode yang digunakan dalam penelitian ini adalah dengan menggunakan metode kuantitatif, sedangkan untuk pengumpulan data dikelompokkan dengan cara menyebarkan kuesioner ke 128 karyawan bagian dari AMT, saya mencatat bahwa nilai median median variabel deskriptif - keselamatan dan kesehatan Pekerjaan adalah 4,12 sedangkan untuk variabel kinerja pegawai sebesar 4,09. Kemudian dari hasil analisis regresi linier sederhana menunjukkan bahwa variabel keselamatan kerja dan kesehatan berpengaruh secara positif terhadap variabel kinerja karyawan, dapat dilihat pada hasil t hitung yaitu sebesar 11.365 dan t tabel 1.9790. Kemudian nilai probabilitas yang dapat ditemukan dalam penelitian ini adalah 0,000 yang berarti bahwa model regresi ini dapat digunakan untuk memprediksi kinerja.
\end{abstract}

Kata Kunci: keselamatan dan kesehatan, kinerja, karyawan

\section{PENDAHULUAN}

Sumber daya manusia merupakan sebuah aset yang penting dan tidak dapat dipisahkan dalam sebuah perusahaan.

*Email korespondensi:

Ulfa Nurul Nissa

Ulfanurulnissa@gmail.com
Perusahaan pasti menyadari bahwa sumber daya manusia yang profesional, terpercaya, berkompeten dan juga tekun merupakan sebuah kunci utama untuk perusahaan mencapai tujuannya. Tujuan tersebut dapat diraih dengan adanya karyawan yang mempuyai kinerja yang sangat tinggi. Untuk 
megelola sumber daya manusia maka diperlukan manajer yang baik.

Hal yang akan dijadikan tolak ukur atas keberhasilan manajemen sumber daya manusia adalah kinerja karyawan. Kinerja karyawan yang baik akan memberikan dampak positif bagi perusahaan, salah satunya adalah peningkatan penyelesaian tanggung jawab yang telah diberikan oleh perusahaan kepada para karyawannya. Apabila dikerjakan dengan sungguh sungguh maka output yang dihasilkan baik. Dijelaskan oleh Sedarmayanti (2010: 236) tentang definisi kinera pada dasarnya "kinerja karyawan merupakan hasil kerja seorang karyawan selama periode tertentu dibandingkan dengan berbagai kemungkinan, misalnya adala standar, target I sasaran, ataupun kriteria yang telah ditentukan dan disepakati bersama".

Adapun faktor untuk meningkatkan kinerja karyawan adalah dengan memperhatikanya faktor keselamatan dan Kesehatan Kerja. Ketika para karyawan mempunyai rasa nyaman dan aman pada saat bekerja maka karyawan tersebut akan merasa tenang dan akan bekerja secara maksimal. Upaya untuk memberikan perlindungan bagi para karyawannya adalah dengan diadakannya program keselamatan dan kesehatan kerja. Program keselamatan dan kesehatan kerja ini mempuyai tujuan untuk melindungi para karyawannya agar selalu sehat dan selamat pada saat melakukan pekerjaan. Dijelaskan oleh (Marwansyah dan Mukaram, 2000) untuk mencapai tujuan program keselamatan dan kesehatan kerja maka perusahaan harus menciptakan lingkungan yang dapat mendukung keselamatan kerja, selain itu adalah membuat lingkungan kerja menjadi aman.

PT Pertamina Patra Niaga (Persero) Ujung Berung merupakan suatu badan usaha milik Negara Republik Indonesia, dan merupakan anak perusaaan PT Pertamina (Persero) dan kegiatan usahanya yang meliputi niaga, pengangkutan, penyimpanan, dan pengolahan perusahaan yang telah beroperasi selama 19 tahun ini. Meyatakan visinya menjadi perusahaan energi dan manajemen logistik terdepan dan mandiri di tau 2017. Serta misi memaksimalkan value chain bisnis energi nasioal melalui kegiatan trading dan logistik di pasar domestik dan global.

Hingga tahun 2017 PT Pertamina Patra Niaga (Persero) Ujung Berung mempunyai pegawai AMT (Armada Mobil Tangki) sebayak 409 (empat ratus sembilan) orang yang bertugas untuk melakukan pelayanan pendistribusian bahan bakar minyak di wilayah Jawa Barat. Jumlah tersebut terbagi kedalam 3 tanggung jawab yang berbeda, AMT (Armada Mobil Tagki) I atau juga sering disebut sebagai supir ini bertugas untuk mengisi BBM (Bahan Bakar Minyak) kedalam mobil tangki dan juga bertugas untuk mengendarai mobil tangki tersebut, kemudian AMT (Armada Mobil Tangki) II disebut sebagai kernet, yang bertugas untuk menemani dan membantu supir pada saat pendistribusian ke SPBU (Stasiun Pengisian Bahan Bakar Umum) dan yang terakhir adalah AMT (Armada Mobil Tangki) on call, yang merupaka supir atau kernet yang akan bekerja pada saat dibutuhkan karena kekurangan AMT (Armada Mobil Tangki) II.

Dalam pendistribusian bahan bakar minyak ini para AMT (Armada Mobil Tangki) I mempunyai beberapa hambatan diantaranya adalah hambatan kecelakaan dan juga kesehatan. Selama bulan Desember 2016 PT Pertamina Patra Niaga (Persero) Ujung Berung telah merekap data kesehatan karyawan bagian AMT (Armada Mobil Tangki) I, yang bisa dilihat pada Tabel 1 .

Tabel 1 Rekap Kesehatan AMT I Bulan Desember 2016

\begin{tabular}{|c|c|c|}
\hline \multicolumn{2}{|c|}{ Penyakit } & \multirow{2}{*}{$\begin{array}{c}\text { Tidak layak } \\
\text { mengantar BBM }\end{array}$} \\
\hline Ringan & Berat & \\
\hline 65 orang & 44 orang & 44 orang \\
\hline
\end{tabular}

Sumber: Data PT Pertamina Patra Niaga (Persero) Ujung Berung, (2017) 
Dari Tabel 1 dapat diketahui bahwa selama bulan Desember 2016 terdapat 65 orang karyawan bagian AMT (Armada Mobil Tagki) I mengalami penyakit ringan. Penyakit ringan ini seperti batuk dan flu. Kemudian terdapat 44 orang karyawan bagian AMT (Armada Mobil Tagki) I megalami penyakit berat dan tidak diperbolehkannya untuk melakukan pengataran BBM (Bahan Bakar Minyak) ke SPBU. Hal ini mengakibatkan keterlambatanya pengiriman BBM (Bahan Bakar Minyak). Kemudian dapat dilihat pada Tabel 2 tentang data kecelakaan yang disebakan oleh karyawan bagian AMT (Armada Mobil Tangki) I selama tahun 2016.

Tabel 2 Rincian Kecelakaan Tahun 2016

\begin{tabular}{|c|c|c|c|c|}
\hline \multirow{3}{*}{ Bulan } & \multicolumn{3}{|c|}{ Kerugian } & \multirow{3}{*}{$\begin{array}{l}\text { Taksiran } \\
\text { Kerugian }\end{array}$} \\
\hline & \multicolumn{2}{|c|}{ Jiwa } & \multirow{2}{*}{$\begin{array}{c}\text { Ken } \\
\text { dara } \\
\text { an }\end{array}$} & \\
\hline & Celaka & Mati & & \\
\hline Jan & $\sqrt{ }$ & & $\sqrt{ }$ & $\mathrm{Rp} \quad 8.000 .000$ \\
\hline Mar & & & $\sqrt{ }$ & $\mathrm{Rp} \quad 9.000 .000$ \\
\hline Apr & & & $\sqrt{ }$ & $\mathrm{Rp} \quad 5.000 .000$ \\
\hline Apr & & & $\sqrt{ }$ & $\mathrm{Rp} \quad 3.000 .000$ \\
\hline Juni & & & $\sqrt{ }$ & Rp 15.000 .000 \\
\hline Sept & & & $\sqrt{ }$ & Rp 10.000 .000 \\
\hline Des & & & $\sqrt{ }$ & $\mathrm{Rp} 30.000 .000$ \\
\hline TOTAL & & & & Rp 80.000.000 \\
\hline
\end{tabular}

Sumber: Olahan Penulis, (2017)

Berdasarkan Tabel 2 dapat diketahui bahwa selama tahun 2016 telah terjadi kecelakaan sebanyak 7 kali, dimana kecelakaan tersebut berjeniskan kecelakaan lalu lintas dan juga kecelakaan kerja. Total kerugian dari kecelakaan selama tahun 2016 adalah sebesar $\mathrm{Rp} 80.000 .000$ dan angka tersebut merupakan angka yang cukup besar.

Berdasarkan uraian latar belakang tersebut, maka identifikasi masalah yang akan menjadi pembahasa daam penelitian ini adalah sebagai berikut:

a. Bagaimana keselamatan dan kesehatan kerja di PT Pertamina Patra Niaga (Persero) Ujung Berung?

b. Bagaimana kinerja karyawan bagian AMT (Armada Mobil Tangki) I di PT
Pertamia Patra Niaga (Persero) Ujung Berung?

c. Bagaimana pengaruh dari keselamatan dan kesehatan kerja terhadap kinerja karyawan AMT (Armada Mobil Tangki) I di PT Pertamina Patra Niaga (Persero) Ujung Berung?

\section{KAJIAN LITERATUR}

\section{Keselamatan dan Kesehatan Kerja}

Marwansyah (2014:

menjelaskan keselamatan (safety) adalah perlindungan untuk para pekerja dari luka yang diakibatkan karena kecelakaan yang terjadi pada saat bekerja. Adapun penjelasan mengenai kesehatan yang dijelaskan oleh Wibowo dan Hardi (2016) bahwa kesehatan kerja merupakan kondisi yang akan berfokus kepada kondisi mental, fisik, emosinola para karyawannya. Dari kedua penjelasan tersebut maka dapat disimpulkan bahwa keselamatan dan kesehatan kerja merupakan perlindungan yang dibuat oleh perusahaan untuk melindungi karyawannya dari kecelakaan kerja dan kondisi kesehatan baik secara fisik maupun mental.

Tujuan keselamatan dan kesehataan kerja yang dijelaskan oleh Suma'mur dalam Paramitha dan Andi (2012) adalah agar setiap pegawai mendapatkan jaminan keselamatan dan kesehatan kerja, agar setiap perlengkapan dan peralatan kerja digunakan sebaik - baiknya, agar semua hasil produksi dipelihara keamanannya, agar adanya jaminan atas pemeliharaan dan peningkatan gizi pegawai, agar meningkatkan kegairahan, keserasian kerja, dan partisipasi kerja, agar terhindar dari gangguan kesehatan yang disebabkan oleh lingkungan kerja.

\section{Kinerja Karyawan}

Secara etimologi kata kinerja ini berasal dari bahasa inggris yaitu job performance (prestasi kerja) adalah suatu hasil pencapaian kerja yang yang sesuai dengan kualitas dan kuantitas tanggung jawabnya, definisi tersebut merupakan penjelasan dari Mangkunegara dalam 
Widodo (2015). Dijelaskan oleh Luthans (2011) kinerja pegawai merupakan suatu kuantitas/ kualitas yang jasanya diberikan oleh seseorang yang sedang melakukan pekerjaan.

Penilaian kinerja merupakan suatu sistem yang formal yang digunakan secara berkala dan digunakan untuk mengevaluasi kinerja para karawa dalam hal menjalankan tugasnya, hal tersebut merupakan pendapat dari Mondy dan Noe dalam Suwatno dan Priansa (2011). Adapun proses penilaian kinerja dimulai dari menggali tujuan yang diinginkan oleh perusahaan, dilanjutkan menetapkan standar yang diharapkan dari suatu jabatan, kemudian langkah selanjutnya adalah menentukan desain yang sesuai untuk untuk mencapai tujuan yang diharapkan oleh perusahaan dan langkah terakhir melakukan penilaian kinerja terhadap karyawan yang berada disuatu jabatan dan hasil penilaian tersebut di analisis dan dikomunikasikan kepada karawannya.

Adapun faktor yang mempengaruhi kinerja yang dijelaskan oleh Widodo (2015: 133) bahwa faktor yang mempengaruhi kinerja adalah faktor kemampuan, dan factor motivasi. Faktor kemampuan (ability) merupkan kemampuan seseorang terdri dari kemampuan1potensi (IQ) dan kemampuan reliality (knowledge1and skill) hal tersebut jika seseorang mempunyai IQ diatas rata rata yang di tunjang dengan pendidikan yang lebih baik maka akan lebih mudah untuk mencapai kinerja yang diinginkan. Faktor motivasi terbentuk dari sebuah sikap seorang karyawan dalam menghadapi situasi kerja. Motivasi ini merupakan sebuah kondisi yang menggerakan diri pegawai yang terarah untuk mencapai tujuan kerja.

\section{Hubungan Keselamatan dan Kesehatan Kerja terhadap Kinerja Karyawan}

Suatu perusahaan akan bergantung kepada karyawan yang dimilikinya, karena karyawan merupakan suatu aset, dan harus dijaga. Salah satu nya adalah dengan cara memperhatikan tentang keselamatan dan kesehatan dalam bekerja. Keselamatan dan kesehatan kerja merupakan sebuah aspek yang penting untuk meningkatkan kinerja karyawan dan dapat melindugi para karyawan untuk terbebas dari kecelakaan di lingkungan yang kurang sehat dan dapat merugikan karyawan maupun perusahaan. Dikemukakan oleh Nurzaman (2014: 290) mengenai definisi keselamatan dan kesehatan kerja adalah terhindarnya hal hal yang menyebabkan terganggunya pegawai dari segi fisik dari mental pada saat melaksanakan pekerjaan dan setelah menunaikan tugas dan kewajiban yang diberikan oleh perusahaan, sedangkan pengertian kesehatan kerja adalah terjaminnya seluruh lingkungan pekerjaan yang menyebabkan sehatnya para pegawai, baik sehat secara fisik maupun sehat secara mental.

Keselamatan dan kesehatan kerja
dengan kinerja karyawan sangat berpengaruh terhadap kemajuan suatu perusaaan, karena kondisi para karyawan yang maksimal akan berpegaruh terhadap hasil kinerja karyawannya, jaminan kesehatan dan keselamatan, dan perusahaan memberikan fasilitas dan kenyamanan yang dapat membuat para karyawan dengan tenang mengerjakan tanggung jawabnya. (Notoatmodjo, 2009) menjelaskan cara peningkatan kinerja seorang pegawai, adalah dengan cara perusahaan membuat lingkungan kerja yang sesuai dengan syarat keselamatan dan kesehatan, jika tidak maka akan terjadi ketidak nyamanan para pegawai, gangguan kesehatan dan kecelakaan yang diakibatkan karena pekerjaan hal tersebut akan membuat turunnya daya kerja.

Berdasarkan pejelasan tersebut maka dapat diketahui bahwa keselamatan dan kesehatan kerja berperan penting dalam peningkatan kinerja karyawan. Perusahaan harus memelihara keselamatan dan keserhtan para karyawanya, kesehatan ini termasuk kesehatan fisik ataupun mental. Jika karyawan mempunyai kesehatan yang tidak baik maka akan mengakibatkan tingkat absensi yang tinggi dan produksi yang 
rendah. Program keselamatan dan kesehatan kerja akan memberikan dampak yang positif baik bagi karyaannya ataupun perusahaan.

\section{Hipotesis}

H0 : Keselamatan dan Kesehatan Kerja tidak berpengaruh secara signifikan terhadap Kinerja Karyawan bagian AMT (Armada Mobil Tangki) I di PT Pertamina Patra Niaga (Persero) Ujung Berung

H1 : Keselamatan dan Kesehatan Kerja berpengaruh secara signifikan terhadap Kinerja Karyawan bagian AMT (Armada Mobil Tangki) I di PT Pertamina Patra Niaga (Persero) Ujung Berung

\section{Metode Penelitian}

Metode yang diguakan dalam penelitian ini adalah metode kuantitatif. Populasi yang diambil merupakan karyawan bagian AMT (Armada Mobil Tangki) I di PT Pertamina Patra Niaga (Persero) Ujung Berung, sedangkan untuk teknik sampel yang digunakan dalam penelitian ini adalah nonprobability sampling. Perhitungan sampel digunakan dengan rumis slovin dan mengasilkan sampel dalam penelitian ini sebanyak 128 orang karyawan bagian AMT (Armada Mobil Tangki) I di PT Pertamina Patra Niaga (Persero) Ujung Berung. Data yang dikumpulkan dalam penelitian ini adalah data primer.

Data primer diperoleh dari perusahaan, yang digunakan sebagai data primer adalah hasil jawaban dari kuesioner yang telah dibagikan kepada responden. Untuk teknis yang digunakan pada penelitian ini adalah sebagai berikut:

1. Analisis Deskriptif

Analisis deskriptif bertujuan utuk mengangalisis data dengan cara menggambarkan data yang telah terkumpul sebagaimana adanya tanpa bermaksud untuk membuat kesimpulan yang berlaku untuk umum, merupakan penjelasan dari (Sugiyono, 2012).

2. Analisis Regresi
Analisis regresi bertujuan untuk mengetahui seberap besarnya pengarh antara variabel keselamatan dan kesehatan kerja (X) terhadap kinerja karyawan (Y). Model regresinya adalah:

$$
Y=\alpha+b X
$$

Keterangan:

Y : Nilai atau subjek dalam variabel dependen yang diprediksikan (kinerja)

$\alpha$ : Konstanta atau bila harga $\mathrm{X}=0$

b : Angka arah atau koefisien regresi yang menunjukkan angka peningkatan ataupun penurunan variabel dependen yang didasarkan pada variabel independen. Bila $b(+)$ maka bila b (-) maka terjadi penurunan

$\mathrm{X}$ : Nilai variabel independen (pelatihan keselamatan dan kesehatan kerja

3. Koefisien Determinasi

Fungsi dari koefisien determinasi adalah untuk mengetahui seberapa besarnya pengaruh antara variabel independen dan variabel dependen (Sugiyono, 2013).

4. Uji Hipotesis

Pengujian hipotesis merupakan jawaban sementara terhadap permasalahan dalam peneltiian ini. Dalam penelitian ini bentuk hipotesis yang digunakan adalah uji t.

a. Uji t

Uji t dalam penelitian ini adalah uji $\mathrm{t}$ untuk satu sampel (one sample t test). Sujarweni (2014) menjelaskan pengujian satu sampel merupkan pengujian nilai tertentu yang diberikan sebagai pembanding akan berbeda secara nyata atau tidak rata - rata sebuah sampel.

\section{Hasil dan Pembahasan} Analisis Deskriptif

Hasil analisis deskriptif adalah untuk menjawab idetifikasi masalah mengenai keselamatan dan kesehatan kerja di PT Pertamina Patra Niaga (Persero) Ujung Berung serta kinerja karyaan bagian AMT 
(Armada Mobil Tangki) I di PT Pertamina Patra Niaga (Persero) Ujung Berung.

Tabel 3 Analisis Deskriptif

\begin{tabular}{|l|l|r|}
\hline \multicolumn{1}{|c|}{ Dimensi } & Mean & $\begin{array}{c}\text { Std } \\
\text { Deviation }\end{array}$ \\
\hline $\begin{array}{l}\text { Keselamatan dan } \\
\text { Kesehatan kerja }\end{array}$ & 4,12 & 0,48 \\
\hline Kinerja Karyawan & 4,09 & 0,486 \\
\hline
\end{tabular}

Sumber: Data Olahan SPSS (2017)

Berdasarkan Tabel 3 maka diperoleh hasil nilai mean variabel keselamatan dan kesehatan kerja adalah sebesar 4,12 dan nilai mean varaiabel kinerja karaywan adalah sebesar 4,09. Nilai mean tersebut berada pada interval 3,41 - 4,20 dan nilai tersebut dapat dikatan baik. Jadi keselamatan dan kesehatan kerja di PT Pertamina Patra Niaga (Persero) Ujung Berung dan Kinerja karyawan bagian AMT (Armada Mobil Tangki) I dinilai baik.

Penilaian baik terhadap variabel keselamatan dan kesehatan kerja ini ditinjau dari 5 dimensi yaitu dimensi pengawasan tingkat keselamatan dan kesehatan, pencegahan penyakit, pencegahan kecelakaan, manajemen tekanan, dan program kesehatan. Kemudian penilaian baik terhadap variabel kinerja karyawan juga ditinjau dari 5 dimensi, yaitu dimensi kuantitas pekerjaan, dimensi kualitas pekerjaan, kemandirian, inisiatif, dan adaptabilitas.

\section{Analisis Regresi}

Fungsi dari analisis regresi ini adalah untuk menghitung besarnya pengaruh antara variabel bebas (keselamatan dan kesehatan kerja) terhadap variabel terikat (kinerja karyawan). Penelitian ini menggunakan analisis regrsi linier sederhana, dimana jumlah variabel pengaruhnya hanya ada satu Tabel 4 merupakan hasil analisis regresi linier sederhana.

Tabel 4 Persamaan Regresi

\begin{tabular}{|c|c|c|c|c|c|c|}
\hline \multirow[b]{2}{*}{ Model } & & \multicolumn{2}{|c|}{ Unstandardized Coefficients } & \multirow{2}{*}{$\begin{array}{c}\begin{array}{c}\text { Standardized } \\
\text { Coefficients }\end{array} \\
\text { Beta } \\
\end{array}$} & \multirow[b]{2}{*}{ t } & \multirow[b]{2}{*}{ Sig. } \\
\hline & & B & Std. Error & & & \\
\hline 1 & (Constant) & 11,221 & 2,628 & & 4,269 & .000 \\
\hline & Variabel K3 & .514 & .045 & .711 & 11,365 & ,000 \\
\hline
\end{tabular}

Jurnal Riset Bisnis \& Investasi

Vol. 3, No. 3, Desember 2017

ISSN 2460-8211
Sumber: Olahan Data SPSS (2017)

Dari Tabel 4 menjelaskan tentang persamaan regresi pengaruh variabel keselamatan dan kesehatan kerja terhadap kinerja karyawan. Dari Tabel 4 tersebut dapat diketahui bahwa nilai konstanta adalah 11.221 (a) dengan koefisien regresi linier sebesar20.711 (b). Dari hasil tersebut dapat diperoleh model regresi sederhana adalah sebagai berikut:

$Y=a+b X$

$Y=11.221+0.711 X$

Persamaan regresi sederhana dapat diketahui nilai kostanta adalah sebesar 11,221 dan koefisien regresi adalah 0,711. Dari persamaan tersebut menjelaskan bahwa tidak adanya perubahan pada variabel keselamatan dan kesehatan kerja atau dapat dikatakan $\mathrm{X}=0$, maka kinerja karyawan yang dicapai adalah sebesar 11,221 dan ketika ada peningkatan 1 unit dari variabel keselamatan dan kesehatan kerja akan meningkatkan kinerja karyawan sebanyak 0.711 .

Tabel 5 Hasil Koefisien Determinasi

\begin{tabular}{|l|c|r|r|r|}
\hline Model & $R$ & R Square & $\begin{array}{c}\text { Adjusted R } \\
\text { Square }\end{array}$ & $\begin{array}{c}\text { Std. Error of } \\
\text { the Estimate }\end{array}$ \\
\hline 1 &, $711^{\mathrm{a}}$ &, 506 &, 502 & 3,429 \\
\hline
\end{tabular}

Sumber: Hasil Olah Data SPSS (2017)

\section{Koefisien Determinasi}

Tujuan dari koefisien determinasi adalah untuk mengukur besarnya pengaruh variabel keselamatan dan kesehatan kerja terhadap kinerja karyawan. Didalam penelitian ini koefisien determinasi digunakan utnuk mengetahui besarnya presentase variabel kinerja karyawan yang dapat diprediksi dengan menggunakan variabel keselamatan dan kesehatan kerja. Tabel 5 berikut ini merupakan hasil dari koefisien determinasi.

Hasil dari penelitian ini dapat diketahui bahwa nilai $R$ Square (angka korelasi yang dikuadratkan atau sebesar $0.711^{2}$ ) adalah sebesar 0.506 atau jika dipersenkan menjadi 50.2\%. Angka tersebut menunjukkan bahwa sebanyak $50.3 \%$ 
kinerja pegawai dapat dijelaskan dengan menggunakan variabel keselamatan dan kesehatan kerja, sedangkan sisanya sebanyak $49.8 \%$ merupakan pengaruh dari faktor lain. Untuk besarnya $R$ Square berkisar antara 0 hingga 1 , dimana semakin kecil nilai $R$ Square maka hubungan antara kedua variabel semakin rendah,begitu pula sebaliknya.

\section{Uji Hipotesis}

Pengujian hipotesis merupakan bagian penting dalam penelitian, setelah data terkumpul dan diolah. Kegunaan utamanya adalah untuk menjawab hipotesis yang dibuat oleh peneliti. Uji hipotesis dalam penelitian ini digunakan dengan uji $\mathrm{t}$

\section{Uji t}

Dasar untuk pengambilan keputusan mengenai uji $\mathrm{t}$ adalah jika $\mathrm{t}$ hitung $<\mathrm{t}$ tabel maka $\mathrm{H} 0$ diterima, tetapi sebaliknya jika $t$ hitung > t tabel maka HO ditolak.

Tabel 6 Hasil Uji t

\begin{tabular}{|c|c|c|c|c|c|c|c|c|}
\hline \multirow[b]{2}{*}{ Model } & & \multicolumn{2}{|c|}{ Unstandardized Coefficients } & \multirow{2}{*}{$\begin{array}{c}\text { Standardized } \\
\text { Coefficients }\end{array}$} & \multirow[b]{2}{*}{$t$} & \multirow[b]{2}{*}{ Sig. } & \multicolumn{2}{|c|}{ Collinearity Statisitics } \\
\hline & & B & Std. Error & & & & Tolerance & VIF \\
\hline 1 & (Constant) & 11,221 & 2,628 & & 4,269 & 000 & & \\
\hline & Variabel K3 & .514 & .045 & , 111 & 11,305 &, 000 & 1,000 & 1,000 \\
\hline
\end{tabular}

Sumber : Hasil Olah Data SPSS (2017)

Dari Tabel 6 dapat diketahui bahwa nilai t hitung dengan nilai signifikansi 0.05 dengan $\mathrm{df}=128-2=126$. Dapat dilihat nilai t hitung sebesar 11,365 dan t tabel yang dijelaskan oleh Ghazali (2013: 470) adalah sebesar 1.9790. Hal ini menunjukkan bahwa t hitung lebih besar dari $t$ tabel. Maka dapat disimpulkan bahwa $\mathrm{H} 0$ ditolak dan $\mathrm{H} 1$ diterima atau dapat dikatakan bahwa terdapat pengaruh yang positif antara keselamatan dan kesehatan kerja terhadap kinerja karyawan bagian AMT (Armada Mobil Tangki) I di PT Pertamina Patra Niaga (Persero) Ujung Berung. Kemudian nilai probabilitias adalah 0.000 dan nilai tersebut jauh lebih kecil dari 0.05 maka model regresi dapat digunakan untuk memprediksi kinerja karyawan atau keselamatan dan kesehatan kerja berengaruh terhadap kinerja karyawan.

\section{Pengaruh antara Variabel Keselamatan dan Kesehatan Kerja terhadap Kinerja Karyawn}

Hasil penelitian yang telah dilakukan, diketahui bahwa keselamatan dan kesehatan kerja mempunyai pengaruh yang positif terhadap kinerja karyawan bagian AMT (Armada Mobil Tangki) I di PT Pertamina Patra Niaga (Persero) Ujung Berung. Hal tersebut dapat menjelaskan bahwa ketika kinerja para karyawan itu meningkat maka keselamatan dan kesehatan kerja karyawanpun akan meningkat. (Handoko, 2012) menjelaskan kinerja karyawan dipegaruhi oleh lingkungan fisik yang berfokus kepada keselamatan dan kesehatan kerja. Adapun penelitian terdahulu yang dijadikan sebagai referensi bagi penulis menyatakan bahwa keselamatan dan kesehatan kerja berpengaruh terhadap kinerja karyawan dan mempunyai hubungan yang signifikan antar variabel.

Hasil dari analisis regresi linier sederhana maka dapat diperoleh model regresi yaitu $Y=11.221+0.711 \mathrm{X}$. Persamaan tersebut dapat disimpulkan bahwa jika tidak adanya keselamatan dan kesehan kerja maka akan dihasilkan kinerja karyawan sebesar 11.221, dan jika terjadi peningkatan kinerja karyawan bagian AMT (Armada Mobil Tangki) di PT Pertamina Patra Niaga (Persero) Ujung Berung sebesar 0.711 .

Hasil dari regresi linier sederhana menunjukkan $R$ Square sebesar 0.506 atau sebesar atau jika dipersenkan menjadi $50.2 \%$. Angka tersebut menunj ukkan bahwa sebanyak $50.2 \%$ keselamatan dan kesehatan kerja karyawan bagian AMT (Armada Mobil Tangi) I di PT Pertamina Patra Niaga (Persero) Ujung Berung berkontribusi terhadap kinerja karyawan. Sedangkan $40.8 \%$ dipengaruhi oleh faktor lainnya yang tidak ada dalam laporan penelitian ini. Nilai dari $R$ Square berkisar antara $0-1$, artinya adalah jika semakin kecil angka $R$ Square, 
maka kedua variabel akan semakin rendah, begitu pula sebaliknya. Hasil dari penelitian ini menunjukkan nilai $R$ Square sebesar 0.711. Dijelaskan oleh (Sugiyono, 2012) bahwa nilai korelasi yang berada pada interval $0.60-0.799$ dikatakan adanya hubungan korelasi yang sangat kuat.

Hasil dari uji T maka dapat diketahui bahwa nilai t hitung sebesar 11.365 dan $\mathrm{t}$ tabel sebesar 1.9790 yang merupakan penjelasan dari Ghazali (2013: 470). Dari data tersebut maka dapat disimpulkan bahwa t hitung > t tabel, atau $11.365>1.9790$. Maka dapat disimpulkan bahwa H0 ditolak dan H1 diterima atau Keselamatan dan Kesehatan Kerja berpengaruh posititif pada Kinerja Karyawan bagian AMT (Armada Mobil Tangki) di PT Pertamina Patra Niaga (Persero) Ujung Berung. Untuk dasar pengambilan keputusan probabilitias jika $\mathrm{H} 0$ diterima jika nilai probabilitas $>0.05$, dan jika H0 ditolak jika probabilitas $<0.05$. Dalam penelitian ini probabilitasnya 0.000 jadi model regresi ini dapat digunakan untuk memprediksi kinerja karyawan.

\section{KESIMPULAN DAN SARAN Kesimpulan}

1. Keselamatan dan kesehatan kerja di PT Pertamina Patra Niaga (Persero) Ujung Berung baik, dilihat dari hasil analisis deskriptif yang mempunyai nilai rata rata 4,12 dari 5 dimensi. Kelima dimensi tersebut adalah pengawasan tingkat keselamatan dan kesehatan, pencegahan kecelakaan, pencegahan penyakit, manajemen tekanan, dan program kesehatan. Dari kelima dimensi tersebut yang mempunyai nilai rata - rata tertinggi adalah pengawasan tingkat keselamatan dan kesehatan kerja sebesar 4,28 , sedangkan untuk nilai rata - rata terendah adalah program kesehatan dengan rata-rata 3,94 .

2. Kinerja karyawan bagian AMT (Armada Mobil Tangki) I di PT Pertamina Patra Niaga (Persero) Ujung Berung baik, hal ini dilihat dari hasil analisis deskriptif yang mempunyai nilai rata - rata 4,09.
Pada variabel kinerja karyawan terdapat 5 dimensi, yaitu kuantitas pekerjaan, kualitas pekerjaan, kemandirian, inisiatif, dan adaptabilitas. Dari kelima dimensi tersebut yang mempunyai nilai rata - rata tertinggi adalah adaptabilitas yaitu sebesar 4,17 dan rata-rata terendah adalah inisiatif dengan rata-rata sebesar 3,98 .

3. Dari hasil uji t, diketahui bahwa variabel keselamatan dan kesehatan kerja berpengaruh positif terhadap kinerja karyawan dengan hasil $\mathrm{t}$ hitung $>\mathrm{t}$ tabel atau 11,365>1,9790. Hal ini menunjukkan bahwa thitung lebih besar dari $\mathrm{t}$ tabel, dan dapat disimpulkan bahwa H0 ditolak dan H1 diterima atau Keselamatan dan Kesehatan Kerja berpengaruh posititif pada Kinerja Karyawan bagian AMT (Armada Mobil Tangki) di PT Pertamina Patra Niaga (Persero) Ujung Berung. Hasil dari penelitian ini dapat diketahui bahwa nilai $R$ Square (angka korelasi yang dikuadratkan atau sebesar $0.711^{2}$ ) adalah sebesar 0.506 atau jika dipersenkan menjadi 50.2\%. Angka tersebut menunjukkan bahwa sebanyak $50.3 \%$ kinerja pegawai dapat dijelaskan dengan menggunakan variabel keselamatan dan kesehatan kerja, sedangkan sisanya sebanyak $49.8 \%$ merupakan pengaruh dari faktor lain. Faktor lain tersebut adalah lingkungan eksternal dan internal perusahaan, dan juga disiplin kerja karyawan.

\section{Saran}

1. Dilihat dari variabel keselamatan dan kesehatan kerja indikator terendah adalah program kesehatan, dengan nilai rata-rata sebesar 3,94 yaitu indikator penurunan berat badan. Diharapkan perusahaan dapat memfasilitiasi sarana olahraga di lingkungan kerja seperti lapangan sepak bola, sarana gym.

2. Dilihat dari variabel kinerja karyawan indikator terendah berada pada dimensi inisiatif dengan rata-rata sebesar 3,98 
dengan indikator fleksibilitas berfikiri. Diharapkan bagi perusahaan untuk membuat kotak saran bagi para karyawannya untuk memberikan ide-ide atau gagasan yang nantinya akan menguntungkan perusahaan itu sendiri, menyediakan evaluasi mengenai masalah, dan mengadakan acara ghatering dan outbound.

\section{DAFTAR PUSTAKA}

Ghazali, I. (2013). Aplikasi Multivariate dengan Program IMB SPSS. Semarang: Badan Penerbit Undip.

Handoko, T. (2012). Manajemen Personalia dan Sumber Daya Manusia. Yogyakarta: BPFE.

Luthans, F. (2013). Organizational Behaviour: An Evidance - Based Approach. New Yotk: The McGrow-Hill Companies, Inc.

Marwansyah. (2014). Manajemen Sumber Daya Manusia. Bandung: CV Alfabeta.

Marwansyah, \& Mukaram. (2000). Manajemen Sumber Daya Manusia. Bandung: Pusat Penerbit Administrasi Niaga.

Nurzaman, K. (2014). Manajemen Personalia. Bandung: CV Pustaka Setia.

Paramita, C. P., \& Wijayanto, A. (2012). Pengaruh Keselamatan dan Kesehatan Kerja terhadap Prestasi Kerja Karyawan pada PT PLN (Persero) APJ Semarang. Jurnal Administrasi Bisnis, 1(1), 1 - 11.

Sedarmayanti. (2010). Manajemen Sumber Daya Manusia, Reformasi Birokrasi dan Manajemen Pegawai Negeri Sipil. Bandung: PT Refika Aditama.

Sugiyono. (2012). Metode Penelitian Pendidikan . Bandung: CV Alfabeta.

Sugiyono. (2013). Metode Penelitian Bisnis. Bandung : CV Alfabeta.

Sujarweni, W. (2014). SPSS Untuk Penelitian. Yogyakarta: Pustaka Baru Press.

Suma'mur. (2009). Higiene Perusahaan dan Kesehatan Kerja (Hiperkes). Jakarta: CV Sagung Seto.
Suwatno, \& Priansa, D. J. (2011). Manajemen SDM dalam Organisasi Publik dan Bisnis. Bandung: CV Alfabeta.

Wibowo, E., \& Utomo, H. (2016). Pengaruh Keselamatan dan Kesehatan Kerja terhadap Kinerja dengan Kepuasan Kerja sebagai Variabel Intervening Studi Kasus pada Karyawan bagian Produksi Serbuk Effervescent PT Sido Muncul Semarang. Among Makart, 9(27), 38 59.

Widodo, S. E. (2015). Manajemen Pengembangan Sumber Daya Manusia. Yogyakarta: Pustaka Pelajar. 